\title{
Sick but yet at work. An empirical study of sickness presenteeism
}

\author{
Gunnar Aronsson, Klas Gustafsson, Margareta Dallner
}

\begin{abstract}
Study objective-The study is an empirical investigation of sickness presenteeism in relation to occupation, irreplaceability, ill health, sickness absenteeism, personal income, and slimmed down organisation. Design-Cross sectional design.

Setting-Swedish workforce.

Participants-The study group comprised a stratified subsample of 3801 employed persons working at the time of the survey, interviewed by telephone in conjunction with Statistics Sweden's labour market surveys of August and September 1997. The response rate was 87 per cent.
\end{abstract}

Main results-A third of the persons in the total material reported that they had gone to work two or more times during the preceding year despite the feeling that, in the light of their perceived state of health, they should have taken sick leave. The highest presenteeism is largely to be found in the care and welfare and education sectors (nursing and midwifery professionals, registered nurses, nursing home aides, compulsory school teachers and preschool/primary educationalists. All these groups work in sectors that have faced personnel cutbacks during the 1990s). The risk ratio (odds ratio (OR)) for sickness presenteeism in the group that has to re-do work remaining after a period of absence through sickness is 2.29 (95\% CI 1.79, 2.93). High proportions of persons with upper back/neck pain and fatiguel slightly depressed are among those with high presenteeism $(p<0.001)$. Occupational groups with high sickness presenteeism show high sickness absenteeism ( $\rho$ $=0.38 ; \mathrm{p}<.01$ ) and the hypothesis on level of pay and sickness presenteeism is also supported $(\rho=-0.22 ; p<0.01)$.

Conclusions-Members of occupational groups whose everyday tasks are to provide care or welfare services, or teach or instruct, have a substantially increased risk of being at work when sick. The link between difficulties in replacement or finding a stand in and sickness presenteeism is confirmed by study results. The categories with high sickness presenteeism experience symptoms more often than those without presenteeism. The most common combination is low monthly income, high sickness absenteeism and high sickness presenteeism. (F Epidemiol Community Health 2000;54:502-509)
Working life in Sweden has changed in many respects during the 1990s. High unemployment, restructuring in both the private and public sectors, slimmed down organisations, a reduced number of public employees, an increased number of people on time restricted employment contracts, and reduced job security are some aspects of the recent transformation. The work environment surveys of Statistics Sweden and Sweden's National Board of Occupational Safety and Health, which have been performed every other year since 1989 show, for example, that the proportion of people perceiving their jobs as stressful and time pressurised has been on the increase. ${ }^{12}$

A number of changes to the sickness compensation system have also been made during the 1990s. Before 1991 the benefit level was 90 per cent of income. In March 1991 a reduced benefit level was introduced for the first three days of absence. In March 1991 employers took over responsibility for providing compensation for the first 14 days of sickness. A so called "qualifying" day-that is, a day of waiting before eligibility for sickness benefit - was introduced in 1993, and the concept of occupational injury was made more restrictive in the same year. In 1996 the amount of benefit was set at 75 per cent of income shortfall, rather than varying throughout the sickness period as it had done before. In January 1997 the sick leave period was extended to 30 days. Both sickness absenteeism and the reporting of occupational injuries have fallen considerably since these rule/ compensation changes. It is, however, difficult to obtain a reliable statistical picture of the overall extent of and change in sickness absenteeism. One of the main reasons for this is that the disposition of companies (above all small companies) to report absences of less than 14 days to the central authority is presumed to have declined, on the grounds that employing organisations are no longer directly compensated for the sickness compensation they pay out from public funds. A further complication is that the length of the employer's period responsibility for payment of sickness compensation has been changed.

In the wake of these changes, and in the light of pressurised situations in the workplace and in relation to personal finances, there are suspicions that people are changing their health/sickness behaviours and related patterns of action. Several such phenomena have been observed. High unemployment and difficulty in changing job seem to constitute the background to the phenomenon of being "locked in", meaning that people remain in an 
occupation they no longer perceive as desirable. From a previous study clear health differentials emerged between groups of permanent employees in and not in their preferred occupation and relations have been found between being locked in and symptoms of ill health. ${ }^{3}$ A further action pattern is that of working unpaid overtime, with many white collar workers putting in more hours than those for which they have agreed wage compensation. ${ }^{4}$ The changed worklife climate of the 1990s has also turned sickness presenteeism into a topical subject. The concept has been used to designate the phenomenon of people, despite complaints and ill health that should prompt rest and absence from work, still turning up at their jobs. Even during the 1980s, when sickness absenteeism in Sweden was many times higher than it is now, Bengt Edgren $^{5}$ used the concepts of "disposition to be present" and "need to be absent" to analyse the effects of sickness absenteeism on health. Edgren regarded short-term absence from a coping perspective, and saw it as providing the person with an opportunity to regulate workload. He identified a group whose absence was too low, which resulted in stress symptoms, but was also able to find a group with optimal sickness absence from a health perspective.

Few studies have so far been performed on the basis of the concept of sickness presenteeism and with an intention to identify the extent of sickness presenteeism. But, in one study of compulsory school and high school teachers (performed in 1993) it was found that both sickness absenteeism and sickness presenteeism were several times higher among a group of teachers with self reported poor ability to wind down and recuperate than in a group without such a problem. ${ }^{6}$ A further study, one performed by Sweden's National Board of Occupational Safety and Health ${ }^{7}$ investigated so called "zero injuries"-that is, occupational injuries not leading to the taking of sick leave. It was found that 46 per cent of zero injuries in 1992 were incurred in the health, welfare and social services sectors, which-given the size of these sectors in relation to the national economy - can be presumed to be a considerable over-representation.

The primary aims of this study are to examine the extent of sickness presenteeism-as measured by the person's own assessment of their state of health - and to investigate the relations between sickness presenteeism and various work characteristics and demographic factors. Several hypotheses can be posed in this context, and are more or less empirically testable within the confines of the study. A first is that working in so called "human service organisations" (HSOs) - that is, ones where people's work tasks include caring for, helping, instructing or providing services to other people-generates a greater disposition to work when sick (for an overview of HSO theory, see, for example, Hasenfeld, ${ }^{8}$ Söderfeldt et $a l,{ }^{9}$ Bejerot. ${ }^{10}$ Fundamental in human service work is that it is concerned with relationships between people. ${ }^{11}$ This basic feature of a HSO creates a tie between the worker and their care recipients, clients, pupils, and so on. This may be supposed to reduce the disposition to be absent from work, and thereby amplify any tendency to sickness presenteeism.

A second hypothesis is that degree of replaceability has a part to play-that is, the extent to which work not performed because of absence must be caught up with by the person on their return. Low replaceability might be expected to be associated with high sickness presenteeism.

A third hypothesis is that income level is significant. The financial loss of being absent from work has a greater impact on the low paid (who have narrower personal financial margins), and accordingly their disposition to presenteeism might be expected to be higher. In this study, this hypothesis can only be tested at an aggregate, not an individual, level.

The issue of replaceability is in part connected with slimmed down and understaffed organisations, and the question arises of whether disposition to work when sick is higher among organisations of this kind. For example, there is evidence from a Finnish study within the public sector that personnel cutbacks accompanying downsizing are associated with medically confirmed negative health outcomes and a more than doubled risk of sickness absenteeism among persons remaining at work. ${ }^{12}$ For the current study, there were no data that could be used to establish whether individual employees were members of organisations diminishing in size. Accordingly, the question is discussed solely in general terms.

The questions posed above are concerned with the external driving forces and motives underlying sickness presenteeism. But, naturally, there is also an interest within the field of health sciences. Is sickness presenteeism behaviour associated with either sickness absenteeism or ill health? The former relation is analysed in this study by correlating sickness presenteeism data with aggregated sickness absenteeism data at occupational group level. The latter kind of relation-between sickness presenteeism and ill health-will for the main part be examined in a forthcoming report (unpublished data).

The further hypotheses posed concerning external conditions can be regarded as nonexclusive and additive - that is, the greater the number of relevant factors that apply, the greater will be the disposition to sickness presenteeism.

\section{Methods}

SAMPLE

The study group comes from Statistics Sweden's monthly labour market surveys (AKU) of August and September 1997, and comprises a stratified subsample of 3801 employed persons working at the time of the survey (see table 1). Approximately 15 per cent of the Swedish workforce consist of persons in temporary employment, but this proportion was weighted upwards by means of stratification for the purposes of this study, so that persons in time restricted employment constituted 50.6 per cent of the sample. The stratification was 
performed to obtain sufficiently large subgroups in the various categories of temporary employees. In the group of permanent employees, the proportions of men and women are roughly the same. Among persons in time restricted employment the proportion of women is 61 per cent. Taking the group as a whole, the proportion of women is 55 per cent $(n=2086)$, and of men 45 per cent $(n=1715)$. For some of the analyses, stratification by form of employment entailed utilisation of Statistics Sweden's weighting ratios with regard to sampling probability. The same dataset is being used to investigate various other issues related to comparison between permanent and temporary employees (work in progress). Per cent tables of sickness presenteeism are based on full sample $(n=3801)$. To avoid excessive uncertainty in the logistic regression, results for occupational groups with less than 22 members were not considered. This left 42 relatively large occupational groups for the analyses, the results of which were grouped into a total of six sectors. This means that the focus of the study is on large occupational groups. Nevertheless, the 42 occupational groups treated in the analysis cover 90 per cent of the full sample. Vacation workers, other less frequent forms of employment and partially missing were not encompassed by this analysis. It reduced the full sample to 3372. These numbers are used into the multiple logistic regression.

SURVEY QUESTIONS

Regular questions posed in Statistics Sweden's labour market surveys (for a description see SCB $)^{13}$ cover personal background factors, kind of employment, sector, occupation (SSYK code), employer, and so on. To these were added questions from other of the statistical agency's studies (including its work environment survey).

Sickness presenteeism is the study's dependent variable, and the following question was posed in relation to it:

Has it happened over the previous 12 months that you have gone to work despite feeling that you really should have taken sick leave due to your state of health? Responses on a four point scale: No, never (1), Yes, once (2), Yes, 2-5 times (3), Yes, more than 5 times (4). The response scale was dichotomised for the purpose of logistic regression $(0=\mathrm{No}$, never/Yes, once, 1 = Yes, $2-5$ times/Yes, more than 5 times).

A further question was posed concerning replaceability in case of absence from work:

If you are absent from work for up to a week what proportion of your tasks must you take up again on your return? Responses on a four point scale: None or only a small proportion (1), Somewhat less than half (2), Somewhat more than half (3), Virtually all (4).

Five questions were posed concerning ill health. Statistics Sweden has used these questions in their biannually work environmental studies since 1989. All items score high on validity and reliability. ${ }^{2}$

Has it happened over the previous three months that you have had heartburn, acid indi- gestion, smarting pain in the pit of the stomach or upset stomach?

Has it happened that you experience discomfort to go to work?

Has it happened over the previous three months that you have had difficulties to sleep because thoughts of your work have kept you awake?

Has it happened that you have upper back pain or pain in the neck after work?

Has it happened over the previous three months that you have been tired and slightly depressed?

Responses to all five symptom questions were measured on a three point Likert scale with regard to their appearance: at least a couple of days a week (1), one day a week or a couple of days a month (2), seldom or not at all (3). Symptom responses were then dichotomised into the following categories $0=$ seldom $/$ not at all and 1=at least a couple of days a week/one day a week or a couple of days a month.

Participants were requested to specify their form of employment on the questionnaire form. Permanent and "time restricted" employees were compared in the analyses, the latter in some cases being divided up into the following five subgroups: substitutes (without permanent position) (1), in probationary employment (2), employed on projects, etc (3), seasonal workers (4), and "to meet emergency requirements" (5). Other less frequent forms of employment were not encompassed by the analyses.

For this study, a further question was posed on whether the person was in their desired workplace. Accordingly, permanent employees were divided into two subcategories: permanent employees in their preferred occupation and in their desired workplace, and other permanent employees. Ages were broken down into five categories; 16-25 years (1), 26-35 (2), 36-45 (3), 46-55 (4), and 56-65 (5).

An education variable was created with five categories: compulsory school (1), high school of two years or less (2), high school of more than two years (3), post high school of three years or less (4), and post high school of more than three years - that is, postgraduate studies (5).

Occupational affiliation was determined according to the standard Swedish occupational classification (SSYK).

INFORMATION ON INCOME AND SICKNESS ABSENTEEISM

Information on sickness absenteeism for each occupational group was self reported and obtained from special processing runs performed by Statistics Sweden's (SCB) labour market surveys on 1997 data. Sickness absenteeism is expressed as the proportion of time absent through sickness in agreed working time in a particular occupation during week of measurement as converted by SCB into a yearly average aggregate level, annual mean 1997. Data on personal income (for 1996) come from Statistics Sweden's earnings yearbook, ${ }^{14}$ income being expressed as average monthly pay for each occupational group (aggregate level). That the information came 
Table 1 Has it happened over the previous 12 months that you have gone to work despite feeling that you really should have taken sick leave due to your state of health? Percentage distribution of answers: No, never, Yes, once, Yes, 2-5 times and Yes, more than 5 times

\begin{tabular}{|c|c|c|c|c|c|}
\hline Variable & No, never & Yes, once & $\begin{array}{l}\text { Yes, } 2-5 \\
\text { times }\end{array}$ & $\begin{array}{l}\text { Yes, more than } 5 \\
\text { times }\end{array}$ & $p$ Value * \\
\hline \multicolumn{6}{|l|}{ Gender } \\
\hline Women $(n=2086)$ & 49 & 13 & 30 & 8 & \\
\hline $\operatorname{Men}(n=1715)$ & 52 & 13 & 29 & 6 & $\mathrm{p}<0.001$ \\
\hline \multicolumn{6}{|l|}{ Age (y) } \\
\hline $16-25(n=936)$ & 65 & 12 & 20 & 3 & \\
\hline $26-35(n=1035)$ & 43 & 17 & 35 & 5 & \\
\hline $36-45(n=755)$ & 46 & 13 & 33 & 8 & \\
\hline $46-55(n=758)$ & 51 & 11 & 28 & 10 & \\
\hline $56-65(n=317)$ & 60 & 9 & 22 & 9 & $\mathrm{p}<0.001$ \\
\hline \multicolumn{6}{|l|}{ Children at home } \\
\hline Yes $(n=1609)$ & 46 & 13 & 33 & 8 & \\
\hline No $(n=2192)$ & 54 & 13 & 26 & 7 & $\mathrm{p}<0.001$ \\
\hline \multicolumn{6}{|l|}{ Education } \\
\hline Compulsory school $(\mathrm{n}=813)$ & 56 & 10 & 24 & 10 & \\
\hline High school $\leqslant 2$ years $(n=1234)$ & 46 & 14 & 33 & 7 & \\
\hline High school $>2$ years $(n=719)$ & 54 & 15 & 26 & 5 & \\
\hline Post high school $\leqslant 3$ years $(n=603)$ & 46 & 14 & 33 & 7 & \\
\hline Post high school $>3$ years $(n=400)$ & 52 & 12 & 28 & 8 & $\mathrm{p}<0.001$ \\
\hline \multicolumn{6}{|l|}{ Part time/full time } \\
\hline Full time $(\mathrm{n}=2467)$ & 50 & 14 & 29 & 7 & \\
\hline Part time $(n=1332)$ & 52 & 10 & 29 & 9 & $\mathrm{p}<0.001$ \\
\hline \multicolumn{6}{|l|}{ Trade union affiliation } \\
\hline Not affiliated $(n=858)$ & 61 & 13 & 21 & 5 & \\
\hline $\mathrm{LO}(\mathrm{n}=1637)$ & 49 & 13 & 30 & 8 & \\
\hline $\mathrm{TCO}(\mathrm{n}=943)$ & 48 & 13 & 32 & 7 & \\
\hline $\operatorname{SACO}(n=304)$ & 50 & 17 & 26 & 7 & $\mathrm{p}<0.001$ \\
\hline \multicolumn{6}{|l|}{ Form of employment } \\
\hline $\begin{array}{l}\text { Permanent in preferred occupation and desired } \\
\text { workplace }(n=1171)\end{array}$ & 53 & 13 & 28 & 6 & \\
\hline Other permanent $(n=655)$ & 42 & 14 & 34 & 10 & \\
\hline Substitutes, without permanent position $(n=679)$ & 55 & 15 & 23 & 7 & \\
\hline In probationary employment $(n=136)$ & 58 & 11 & 26 & 5 & \\
\hline Seasonal workers $(n=111)$ & 65 & 8 & 19 & 8 & \\
\hline Employed on projects, etc $(n=343)$ & 55 & 12 & 27 & 6 & \\
\hline To meet emergency requirements $(n=341)$ & 58 & 10 & 26 & 6 & $\mathrm{p}<0.001$ \\
\hline \multicolumn{6}{|l|}{ Employer } \\
\hline State $(n=215)$ & 52 & 12 & 30 & 6 & \\
\hline Municipality $(n=1047)$ & 44 & 12 & 33 & 11 & \\
\hline County council $(n=248)$ & 45 & 11 & 38 & 6 & \\
\hline Private $(n=2291)$ & 54 & 13 & 27 & 6 & $\mathrm{p}<0.001$ \\
\hline
\end{tabular}

${ }^{\star} \mathrm{p}$ Value by Pearson $\chi^{2}$ test (weighted).

from 1996 rather than 1997 can be regarded as insignificant, as there is nothing to suppose that pay conditions changed other than marginally between the years. Physiotherapists/ occupational therapists and social workers/ psychologists were excluded from the earnings comparisons on the grounds that these occupations formed part of wider categories where there was considerable pay dispersion.

\section{STATISTICAL PROCESSING}

Three types of analysis were performed: simple frequencies, cross tabulations with $\chi^{2}$ tests, and multiple logistic regressions. Covariation between sickness presenteeism on the one hand and sickness absenteeism/personal income on the other was analysed by calculating Spearman rank correlation coefficients. Levels are illustrated first through the presentation of percentage based tables, where comparisons are made of sickness presenteeism in relation to background variables, and between different occupations grouped into sectors in relation to presenteeism. In these analyses the two strata in the sample-permanent and time restricted employees - have been weighted according to their sampling probability (as recommended by Statistics Sweden).

The analyses that follow are based on multiple logistic regression with the dependent variable "sickness presenteeism" and a reference group with a value of 1 was determined for each independent variable (the relevant comparison group is presented in each table).

The results of the logistic regression are presented in the form of odds ratios with $95 \%$ confidence intervals (95\% CI). Nagelkerke $r^{2}$ is an attempt to imitate the interpretation of multiple $r^{2}$ and used to determine the proportion of variance explained. ${ }^{15} \mathrm{~A} \chi^{2}$ value is presented for the entire model. ${ }^{16}$ Data processing was performed using SPSS version 8.0.

\section{Results}

SICKNESS PRESENTEEISM AND

DEMOGRAPHIC/SOCIOECONOMIC FACTORS

Table 1 provides an overview of frequency distributions in relation to various background conditions. There is a tendency for women to show slightly higher sickness presenteeism than men. In terms of age, it is primarily people of medium working age who are relatively often present when sick. People with children at home show higher presenteeism than those without children. There is no clear pattern in relation to education. Nor is sickness presenteeism clearly related to working full time or part time. Persons affiliated to Sweden's Confederation of Professional Employees (TCO, senior white collar) and the Swedish Confederation of Trade Unions (LO, blue collar) show somewhat higher presenteeism than the Swedish Confederation of Professional Associations (SACO, junior white collar) and 
Table 2 Percentage distribution* and multiple logistic regression with $^{*}$ the dependent variable "sickness presenteeism" and with occupation, labour market situation, replaceability, part time/full time, gender, age and education as independent variablesf. Odds ratios and confidence intervals (CIs) are presented

\begin{tabular}{|c|c|c|c|}
\hline Independent variable & Number & $\%$ & Odds ratio $(95 \% \mathrm{CI})$ \\
\hline \multicolumn{4}{|l|}{ Occupation according to SSYK code } \\
\hline Managers, $1110-1319 \ddagger$ & 102 & 35 & 1 \\
\hline Care and welfare & 649 & 44 & \\
\hline Medical doctors, 2221 & 28 & 49 & $2.47(0.99,6.15)$ \\
\hline Senior nursing and midwifery professionals, 2231-2236 & 35 & 54 & $3.93(1.72,8.94)$ \\
\hline Social workers and psychologists, $2491-2492$ & 35 & 27 & $1.63(0.70,3.77)$ \\
\hline Physiotherapists and occupational therapists, $3221-3228$ & 35 & 17 & $0.42(0.15,1.20)$ \\
\hline Registered nurses, 3230-3239 & 62 & 49 & $2.71(1.33,5.52)$ \\
\hline Welfare workers and associated professionals, $3461-3462$ & 32 & 52 & $1.93(0.82,4.54)$ \\
\hline Assistant nurses, 5132 & 199 & 47 & $2.89(1.64,5.09)$ \\
\hline Personal care and related workers, 5133 & 170 & 37 & $1.94(1.08,3.49)$ \\
\hline Nursing home aides, 5134 & 53 & 65 & $4.26(2.05,8.86)$ \\
\hline Education & 363 & 46 & \\
\hline College and university teachers, 2310 & 38 & 33 & $0.94(0.40,2.24)$ \\
\hline High school teachers, $2320-2323$ & 46 & 32 & $1.22(0.55,2.70)$ \\
\hline Compulsory school teachers, 2330 & 61 & 52 & $4.55(2.26,9.17)$ \\
\hline Other teachers, $2340-2359$ & 22 & 51 & $2.34(0.88,6.25)$ \\
\hline Pre-primary educationalists, $3310-3320$ & 107 & 55 & $3.59(1.94,6.65)$ \\
\hline Child minders, 5131 & 89 & 38 & $2.26(1.17,4.35)$ \\
\hline Engineering and computing & 202 & 27 & \\
\hline Civil engineers, $2140-2149$ & 22 & 21 & $0.73(0.24,2.21)$ \\
\hline Other engineers, 3110-3119 & 103 & 29 & $0.87(0.47,1.61)$ \\
\hline Computing professionals, 2131-2139 & 43 & 18 & $0.55(0.22,1.33)$ \\
\hline Other electronic-equipment oparators, 3131-3212 & 34 & 39 & $1.88(0.81,4.33)$ \\
\hline Manufacturing and other labourers & 740 & 35 & \\
\hline Building trades workers, $7111-7143$ & 196 & 40 & $1.85(1.07,3.23)$ \\
\hline Welders, metal molders, and mechanics, $7210-7243$ & 133 & 32 & $1.52(0.85,2.73)$ \\
\hline Precision workers, $7311-7435$ & 33 & 30 & $1.34(0.55,3.25)$ \\
\hline Process plant operators, $8111-8170$ & 33 & 27 & $1.18(0.46,3.01)$ \\
\hline Machine operators, assemblers, $8211-8290$ & 193 & 38 & $1.96(1.12,3.41)$ \\
\hline Drivers and other transport operators, $8311-8340$ & 124 & 35 & $1.95(1.06,3.57)$ \\
\hline Manufacturing and other labourers, 9310-9330 & 28 & 34 & $1.01(0.34,2.99)$ \\
\hline Restaurant and service & 348 & 34 & \\
\hline Restaurant services workers, 9130 & 71 & 35 & $1.96(0.96,3.99)$ \\
\hline Cooks and waiters, 5111-5123 & 75 & 40 & $2.87(1.47,5.60)$ \\
\hline Cleaners and other helpers, $9121-9123$ & 96 & 36 & $1.41(0.73,2.72)$ \\
\hline Numerical clerks, 4120 & 40 & 26 & $0.87(0.38,2.01)$ \\
\hline Customer services and information clerks, 4221-4225 & 66 & 30 & $1.40(0.68,2.87)$ \\
\hline Commerce and others & 630 & 36 & \\
\hline Business professionals, $2410-2419$ & 48 & 26 & $0.91(0.43,1.94)$ \\
\hline Agents and brokers, 3412-3416 & 73 & 34 & $1.25(0.65,2.39)$ \\
\hline Banking officials, 3418 & 26 & 53 & $1.50(0.57,3.93)$ \\
\hline Other sales-associate professionals, 3419-3429 & 23 & 42 & $1.46(0.56,3.80)$ \\
\hline Administrative professionals and bookkeepers, $3431-3433$ & 55 & 23 & $0.61(0.28,1.34)$ \\
\hline Other office clerks, 4190 & 104 & 42 & $1.49(0.81,2.76)$ \\
\hline Cashiers and bookkeepers, $4211-4213$ & 37 & 44 & $3.16(1.35,7.39)$ \\
\hline Salespersons, retail and wholesale, 5210-5227 & 140 & 35 & $1.69(0.93,3.08)$ \\
\hline Secretaries, $4111-4112$ & 55 & 26 & $0.92(0.44,1.92)$ \\
\hline Storekeepers, $4131-4140$ & 69 & 46 & $2.47(1.26,4.85)$ \\
\hline \multirow{2}{*}{\multicolumn{4}{|c|}{ Form of employment }} \\
\hline & & & \\
\hline $\begin{array}{l}\text { Permanent in preferred occupation and desired } \\
\text { workplace } \ddagger\end{array}$ & 1153 & 34 & 1 \\
\hline Other permanent & 649 & 44 & $1.49(1.21,1.85)$ \\
\hline Substitutes, without permanent position & 669 & 30 & $0.79(0.62,1.00)$ \\
\hline In probationary employment & 134 & 31 & $1.12(0.73,1.70)$ \\
\hline Seasonal workers & 107 & 27 & $0.95(0.59,1.52)$ \\
\hline Employed on projects, etc & 327 & 33 & $1.09(0.81,1.45)$ \\
\hline To meet emergency requirements & 333 & 32 & $0.93(0.69,1.27)$ \\
\hline \multicolumn{4}{|l|}{ Gender } \\
\hline Women $\ddagger$ & 1873 & 38 & 1 \\
\hline Men & 1503 & 35 & $0.96(0.78,1.17)$ \\
\hline \multicolumn{4}{|l|}{ Age $(y)$} \\
\hline $25-35 \ddagger$ & 951 & 40 & 1 \\
\hline $16-25$ & 706 & 23 & $0.53(0.41,0.67)$ \\
\hline $36-45$ & 710 & 41 & $1.01(0.82,1.24)$ \\
\hline $46-55$ & 715 & 38 & $0.96(0.77,1.19)$ \\
\hline $56-65$ & 290 & 31 & $0.74(0.54,1.01)$ \\
\hline \multicolumn{4}{|l|}{ Education } \\
\hline Compulsory school $\ddagger$ & 693 & 34 & 1 \\
\hline High school $\leqslant 2$ years & 1141 & 40 & $1.28(1.03,1.59)$ \\
\hline High school $>2$ years & 634 & 31 & $1.04(0.80,1.35)$ \\
\hline Post high school $\leqslant 3$ years & 532 & 40 & $1.02(0.75,1.40)$ \\
\hline Post high school $>3$ years & 372 & 36 & $0.81(0.56,1.17)$ \\
\hline \multicolumn{4}{|l|}{ Replaceability ("work left undone") } \\
\hline None or only a small proportion $\ddagger$ & 2100 & 35 & 1 \\
\hline Somewhat less than half & 365 & 36 & $1.26(0.97,1.64)$ \\
\hline Somewhat more than half & 277 & 34 & $1.66(1.22,2.25)$ \\
\hline Virtually all & 630 & 42 & $2.29(1.79,2.93$ \\
\hline Part time/full time & & & \\
\hline Full time & 2197 & 36 & 1 \\
\hline Part time & 1175 & 38 & $1.26(1.05,1.52)$ \\
\hline Total & 3372 & 37 & \\
\hline
\end{tabular}

Occupation category: Nagelkerke $r^{2} 0.066 \chi^{2}(\mathrm{df}=61) 229.11 \mathrm{p}<0.0001$. ${ }^{\star}$ Percentage levels of presenteeism are based on full sample $(\mathrm{n}=3801)$. †Multiple logistic regression are based on reduced sample $(n=3372)$. $\ddagger$ For each independent variable determined the reference category. not affiliated. In relation to form of employment, it is the group in other permanent employment that shows strikingly the highest presenteeism. Seasonal workers show somewhat lower presenteeism. Personnel in local government (municipalities and county councils) are considerably more likely to be present when sick than persons employed in state administrations and in private companies.

SICKNESS PRESENTEEISM AMONG VARIOUS

OCCUPATIONAL GROUPS

Percentage based comparisons

Table 2 shows sickness presenteeism in various groups distributed by sector. It emerges that there are important systematic differences both between specific occupational groups and by sector. The highest sector presenteeism is largely to be found in the education sectors (46 percent; odds ratio $2.16,95 \%$ CI $1.32,3.55)$ and care and welfare (44 per cent; odds ratio $1.93,95 \%$ CI $1.20,3.11)$.

Of the nine occupational groups in the care and welfare sector seven lie at or above the percentage for the whole sector. The greatest sickness presenteeism is displayed by nursing home aides, followed by nursing and midwifery professionals (working in maternity clinics, or emergency, district and child medical care units) and by welfare workers and associated professionals.

There is also high sickness presenteeism among certain occupational groups in the education sector. Pre-primary educationalists, compulsory school teachers and other teachers are at the top in this regard, whereas college/ university teachers and high school teachers are somewhat below the percentage of the entire study group.

The sickness sector presenteeism rates in other sectors are not statistically significant and generally considerably lower than those in education and, care and welfare. Within the commercial sector however, banking officials show remarkably high presenteeism (53 per cent). For banking officials the statistical estimate is uncertain because of subsample size $(n=30)$. In this sector storekeepers, cashiers, other office clerks and other sales associate professionals also have relatively high sickness presenteeism.

The pattern based on simple cross tabulations is highlighted when the material is analysed by means of multiple logistic regression (table 2). As mentioned above, the comparison group - to which a value of 1 is allocated-is managers.

Within care and welfare the relative risk of sickness presenteeism is more than quadrupled for nursing home aides, and virtually quadrupled for nursing and midwifery professionals. For registered nurses and assistant nurses it is nearly threefold. Personal care and related workers also have a strikingly high risk of being present at work when sick. The group of medical doctors has an odds ratio of 2.47 , but because of subsample size the estimate is uncertain by lack of precision.

In the group of compulsory school teachers, the risk of sickness presenteeism is also more 


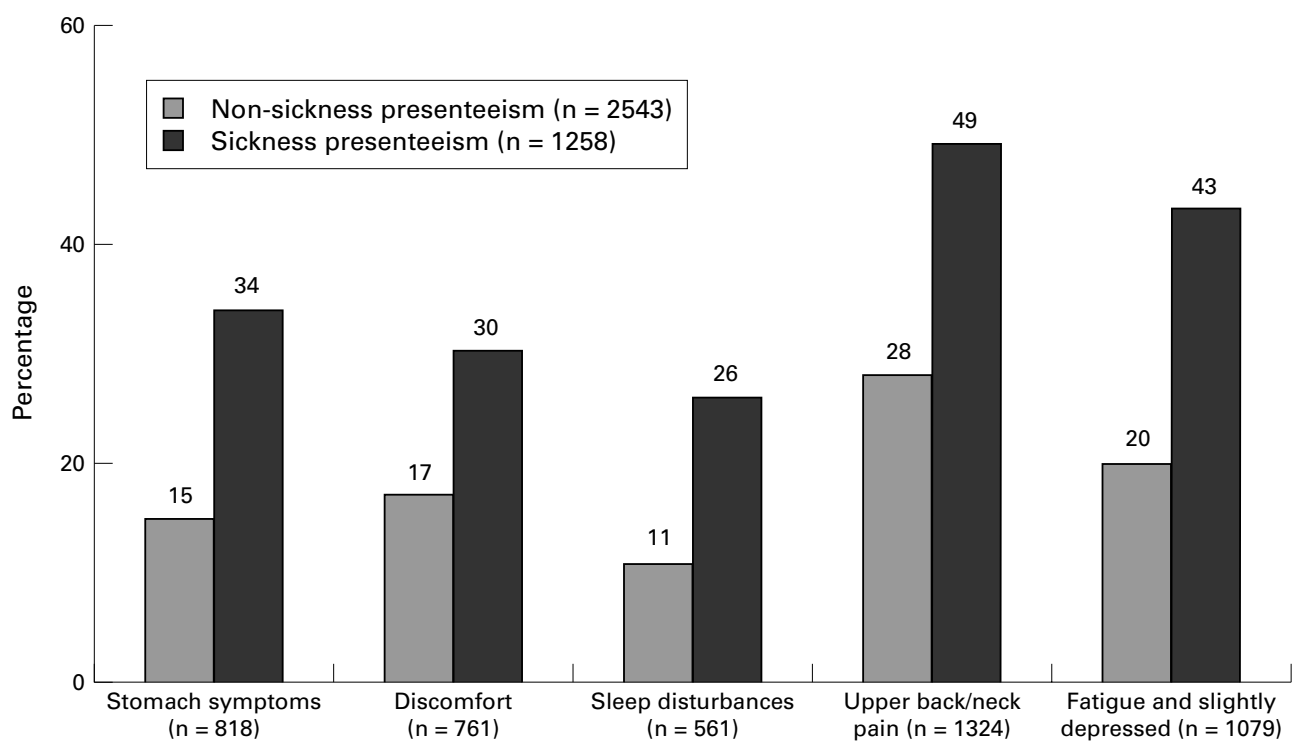

Figure 1 Percentage based comparisons between symptoms and sickness presenteeism (two times or more over the previous 12 months) and symptoms and no sickness presenteeism.

than quadrupled. Pre-primary educationalists (preschool teachers and recreation organisers) and child minders also have a substantially increased risk of being present at work when sick.

Within other occupational sectors there are not the same high risk ratios, although some high levels of risk are recorded for individual occupations. In manufacturing the risk is virtually doubled for drivers and other transport operators (bus, truck, taxi and industrial machine drivers among others), machine operators and assemblers, and building trades workers.

In the restaurant and service sector cooks and waiters show an almost threefold increased risk. Within the commercial sector, cashiers constitute a high risk group (3.16). And for storekeepers the relative risk is doubled.

In the occupational groups with very high sickness presenteeism women are strongly over-represented. Of nursing and midwifery professionals, 90 per cent are women, of registered nurses 88 per cent, of assistant nurses 94 per cent, of personal care and related workers 89 per cent, of nursing home aides 63 per cent, of welfare workers and associated professionals 65 per cent, of compulsory school teachers 73 per cent, of pre-primary educationalists 90 per cent, and of child minders 94 per cent. The high risk group in the commercial sector, cashiers, consists of 96 per cent of women. But the effect of gender in itself is weak in the logisticregression analyses. That many women are often at work when sick is related in the first instance to their occupational affiliation. The data for these analyses are at individual level, which is why conclusions should primarily concern particular women and men. The result implies that presenteeism for women is lower in other occupational groups.

There are also certain tendencies with regard to the background variables. But the odds ratios are relatively low compared with those found by occupational group. The group of permanent employees that in previous studies ${ }^{3}$ has been referred to as "locked in" (persons in a non-preferred job and undesired workplace) is characterised by increased sickness presenteeism, which supports the hypothesis that poor substitutability (difficult to replace) is a ground for sickness presenteeism. The risk ratio for presenteeism in the group that has to re-do all the work remaining after a period of absence through sickness is 2.29 .

SICKNESS PRESENTEEISM AND SYMPTOMS OF ILL HEALTH

The correlation between sickness presenteeism and ill health cannot be completely analysed in this study. It will be examined in a separate report (unpublished data). The first analysis showed (with simple cross tabulation) high correlation between sickness presenteeism and all five symptoms (fig 1). Very high proportions of persons with upper back/neck pain and fatigue/slightly depressed are among those with high sickness presenteeism. $\chi^{2}$ Tests for all symptoms are significant $\mathrm{p}<0.001(\mathrm{df}=1)$.

SICKNESS PRESENTEEISM, SICKNESS ABSENTEEISM AND PERSONAL INCOME

Occupational groups with high sickness presenteeism show high sickness absenteeismnursing home aides, pre-primary educationalists, nursing and midwifery professionals, and welfare workers and associated professionals. The covariation between sickness presenteeism and sickness absenteeism was analysed by calculating Spearman rank correlation coefficients $(\rho=0.38 ; p<.01)$.

The relation between sickness presenteeism and level of pay was also analysed by calculating Spearman's rank correlation coefficients $(\rho=-0.22 ; p<.01)$. Occupational groups with high sickness presenteeism - in the care/ welfare and education sectors, with the exception of medical doctors-lie below or close to the median income level. Medical doctors constitute the only occupational group covered by 
the survey displaying the combination of high pay and high presenteeism. On the income scale the five/six occupational groups that follow medical doctors all lie below the average in terms of presenteeism. All occupational groups below the median in terms of income, however, do not show the same pattern of high sickness presenteeism as persons in the care/ welfare and education sectors.

\section{Discussion}

The two hypotheses that could be directly tested on the basis of the survey material both obtained support. Members of occupational groups whose everyday tasks are to provide care or welfare services, or teach or instruct, have a substantially increased risk of being at work when sick. These are occupations where relationships with other persons play an important part in work outcome. In this context, it can be mentioned that school teachers, in Statistics Sweden's "Work Environment 97" study, were found to report extremely high mental exhaustion in comparison with other occupational groups. Fifty one per cent report fatigue and listlessness each week, and 22 per cent a lack of desire to go to work. Corresponding values for all occupational practitioners are 33 and 15 per cent respectively. ${ }^{2}$ All occupations of this kind, however, do not show this pattern. Rather, it seems primarily to apply to persons in groups who inter-relate with the sick, young and small children, and the elderly - that is, the "client groups" that can be said to be more dependent and vulnerable. The care and welfare and education groups with high risk ratios are relatively poorly paid. A majority of the occupations and activities in question are to be found in the public sector - in municipal and county local government units. The activities involved are also those that were subjected to staffing cutbacks during the 1990s. The results of the presenteeism study coincide with investigations of so called "zero injuries". ${ }^{7}$ Reports of accidents that do not lead to the taking of sick leave are made primarily by nurses, assistant nurses, nursing aides in psychiatric care, personal care workers and child minders - that is, the same groups that were found to show high sickness presenteeism in the current study. Outside education and the care and welfare sector risk ratios are not as high, and the patterns are not as systematic. The relatively few high risk groups that do appear are those where there are known work environment risks with regard to stress and physical workload in combination with relatively low pay. This applies especially, to the group with the highest risk level outside care/welfare and education, namely cashiers of various kinds. Banking officials, who have the highest percentage share of sickness presenteeism outside the education and care and welfare sector, also work in an industry where there have been major personnel cutbacks.

Note, as mentioned above, that the study is restricted to the large occupational groups that it was possible to extract from Statistics Sweden's samples. The findings do not exclude the possibility that there is high sickness
KEY POINTS

- A substantial excess rate of sickness presenteeism was found in care and welfare and education sectors.

- Being hard to replace is related to sickness presenteeism.

- Occupational groups with high sickness presenteeism also show high sickness absenteeism and low monthly income.

- High proportions of persons with upper back/neck pain and fatigue/slightly depressed are among those with high sickness presenteeism.

presenteeism among the numerically smaller occupational groups that have been assembled under "other occupations". A study based on a larger sample would be capable of providing information on this.

A comment should be made on the choice of managers as the comparison group for the occupational comparisons. Firstly, managers are typical of the entire sample with regard to sickness presenteeism. Among managers, 35 per cent were found to have been present when sick on several occasions, which is close to the mean percentage (37) for the entire sample. Secondly, managers are not categorisable by sector as they can be found throughout working life. Accordingly, building a sector specific factor into the comparison group was avoided. Of the managers in the comparison group, 81 came from medium sized companies/ administrations, and 25 from smaller enterprises.

The second hypothesis concerning replaceability is also supported. Effects are particularly noticeable among members of the group that have to "re-do" virtually all work missed in the case of absence through sickness.

The background variables included in the analyses-age, gender, and education-have relatively little or no explanatory value with regard to sickness presenteeism. There are indications, however, of a gender factor. An uneven intra-occupation gender distribution has been shown to be of significance for sickness absenteeism and health. ${ }^{14}$

The hypothesis on level of pay and sickness presenteeism is also supported. All occupational groups within care and welfare and in education-with the exception of medical doctors - are on the lower half of the pay scale or close to the average wage. Medical doctors show a combination of high income and high sickness presenteeism. That high income groups also have high sickness presenteeism is not, however, a general pattern, which speaks for the existence of a combination or reinforcement effect of income and life profession. In this study the relation between level of pay and sickness presenteeism was investigated at aggregated level. For more certain conclusions to be drawn it would be desirable to have data at individual level, which would reveal variation within each occupation.

The significance of downsizing and personnel cutbacks could not be directly tested 
empirically in this study, but - as mentioned above - care/welfare and education have been sectors subjected to savings and cutbacks of this kind. Further research, based on a design capable of generating conclusions concerning the relative importance of these various factors, would be desirable.

There is a lack of previous investigations of sickness presenteeism that would have enabled evaluation of trends and absolute levels in sickness presenteeism. In connection with sickness benefit reforms, however, Sweden's national insurance administration (RFV) conducted a survey (in 1994 - that is, after the reform) in which a question was posed on whether people "had gone to work despite feeling 'a bit under the weather' ". Approximately 60 per cent responded in the affirmative. ${ }^{18}$ The formulation of the RFV question offers a lower threshold for sickness presenteeism than the question used for this study, which is why making direct comparisons with the RFV figures would be a lame exercise.

As well as nature of work, replaceability and pay, there are a number of other factors that might be expected to impact on disposition to be present at work. These should be included in further studies. Kristensen, ${ }^{19}$ for example, refers to stimulation at work, rule systems and control, and also the risk of job loss. Indeed, the latter can be regarded as an aspect of cutbacks and the slimming down of organisations.

A question that is highly relevant both scientifically and practically is whether there is a relation between sickness presenteeism and ill health and between sickness absenteeism and sickness presenteeism. If so, what is the temporal nature of that relation? Is there a risk that the sickness presenteeism of today will become the sickness absenteeism of tomorrow? In this study the analysis showed a positive correlation between self reported sickness presenteeism and sickness absenteeism. Detailed analysis of sickness presenteeism requires more complexity of the model analysis and development of longitudinal studies. No research has yet tackled the question of any such connection. In this cross sectional study, a relatively strong association was found between presenteeism and absenteeism. A reasonable hypothesis is that absence through sickness is health promoting in that it provides scope for physical and mental recuperation after strain or illness. Recent stress research provides ever increasing evidence that a lack of "winding down" and recuperation after episodes of strain makes up an important mediating mechanism in the link between stress and ill health. ${ }^{20}$ There is evidence from experimental studies of significant associations between mental exhaustion and susceptibility to the common cold. ${ }^{21}$ The risks of being at work when sick naturally vary between different types of complaints and dis- eases, and also according to how adaptable work is to a reduction in personal capacity. Associated with the issue of recuperation changes are also questions concerning whether new patterns have been created for avoiding short-term absence, such as compensatory leave, vacation allowances, and changes in work schedules. In the light of the very substantial potential societal costs of even relatively small changes in sickness absenteeism, there is a great need for knowledge on the extent and consequences of such "concealed absenteeism", and also on the nature of any time related association between sickness presenteeism and sickness absenteeism.

Funding: this study was financially supported by the Swedish Council for Work Life Research.

Conflicts of interest: none.

1 Arbetarskyddsstyrelsen, SCB. [The National Board of Occupational Safety and Health, Statistics Sweden]. Arbetsmiljön 1995. Stockholm: Statistiska Centralbyrån (SCB), 1996.

2 Arbetarskyddsstyrelsen, SCB. [The National Board of Arbetarskyddsstyrelsen, SCB. [The National Board of
Occupational Safety and Health, Statistics Sweden]. Arbetsmiljön 1997. Stockholm: Statistiska Centralbyrån (SCB), smiljön 1998.

3 Aronsson G, Göransson S. Permanent employment but not in a preferred occupation: psychological and medical aspects, research implications. F Occup Health Psychol 1999;4:152-63

4 Aronsson G. Paid by time but judged by results: an empirical study of unpaid overtime. International fournal of Employment Studies 1999;1:1-15.

5 Edgren B. Coping-avlastande sjukfrånvaro. Arbete Människa Miljö 1986;1:25-32.

6 Aronsson G, Svensson L. Nedvarvning, återhämtning och hälsa bland lärare i grund- och gymnasieskolan. Arbete och Hälsa 1997;21:1-14.

7 Arbetarskyddsstyrelsen. [The National Board of Occupational Safety and Health]. Nollskador 1992. Solna: Arbetarskyddsstyrelsen. Enheten för arbetsskadestatistik, 1996.

8 Hasenfeld Y. Human service organizations. Englewood Cliffs, NJ: Prentice Hall, 1983.

9 Söderfeldt B, Söderfeldt M, Muntaner C, et al. Psychosocial work environment in human service organizations: a work environment in human service organizations: a conceptual analysis and development of the

10 Bejerot E. Dentistry in Sweden: health work or ruthless effeiciency. [Doctoral thesis]. Malmö: Department of Dental Health, Center for Oral Health Sciences Malmö, 1998.

11 Aronsson G, Astvik W, Thulin A-B. Home care workers: work conditions and occupational exclusion. Home Health Care Services Quarterly 1998;17:71-91.

12 Vahtera J, Kivimäki M, Pentti J. Effect of organisational downsizing on health of employees. Lancet 1997;350:1124-

13 SCB. [Statistics Sweden]. Arbetskraftsundersökningen. Frågeformulär. [Labour-market survey: Questionnaire]. Stockholm: Statistiska Centralbyrån, 1994.

14 SCB. [Statistics Sweden]. Lönestatistisk årsbok 1996, Sveriges officiella statistik. [Statistical yearbook of salaries 1996, Official Statistics of Sweden]. Stockholm: Statistiska Centralbcial Statistics

15 Nagrån, 1997 . ficient of determination. Biometrika 1991;78:691-2

16 Menard SW. Applied logistic regression analysis. Sage University Paper series on Quantitative Applications in the Social Sciences, 07-106. Thousand Oaks, CA: Sage, 1995.

17 Alexanderson K. Sickness Absence in a Swedish county with reference to gender, occupation, pregnancy and parenthood. [ Doctoral thesis]. Department of Community Medicine. Linköping: Linköping University, 1995.

18 RFV. [The National Social Insurance Board]. Effekter och resultat av sjuklönereformen, karensdagen och sänkta kompensationsnivåer inom sjukpenningförsäkringen. RFV Anser. Stockholm: Riksförsäkringsverket, 1995.

19 Kristensen TS. Sygefravær som coping. Socialmedicinsk Tidskrift 1995;72:12-17.

$20 \mathrm{McEwen}$ BS. Protective and damaging effects of stress mediators. N Engl f Med 1998;338:171-9.
median

21 Cohen S, Tyrrell DA, Smith AP. Psychological stress and susceptibility to the common cold. N Engl F Med 1991;325: susceptibitit 